\title{
An efficient strategy for improving the water stability of a near- infrared-emissive lanthanide MOF
}

\author{
Haihuan $\mathrm{Yu}^{1}$, Zhongmin $\mathrm{Su}^{2,3, *}, \mathrm{Xiao} \mathrm{Li}^{2,3}$, \\ ${ }^{1}$ School of Materials Science and Engineering, Changchun University of Science and Technology, Changchun 130022, China \\ ${ }^{2}$ School of Chemistry and Environmental Engineering, Changchun University of Science and Technology, Changchun 130022, China \\ ${ }^{3}$ Jilin Provincial Science and Technology Innovation Center of Optical Materials and Chemistry, Changchun University of Science and \\ Technology, Changchun, 130022, China
}

\begin{abstract}
Near-Infrared-emissive materials have attracted substantial attention due to their unique properties. To solve the urgent requirements of high-water stability materials can be widely used in practical engineering. Hence, a novel near infrared luminescent and highly water-stable lanthanide-organic frameworks (namely Yb-MOF-Y) was synthesized under hydrothermal method by anchoring functionalized, rigid ligands 2,3,5,6-tetrafluoroterephthalic acid and 1,10-phenanthroline onto its skeleton. It is notable that the $\mathrm{Yb}-\mathrm{MOF}-\mathrm{Y}$ possess high structural stability in water for 28 days, in different acid-base solutions $(\mathrm{pH}=$ 4-10) for 3 days and the thermal stability in water $\left(-20^{\circ} \mathrm{C}\right.$ to $\left.60^{\circ} \mathrm{C}\right)$ for 3 days. Remarkably, luminescent studies reveal that the $\mathrm{Yb}-\mathrm{MOF}-\mathrm{Y}$ can be used as a potential material in near infrared field.
\end{abstract}

\section{Introduction}

Lanthanide metal-organic frameworks (Ln-MOFs) as a unique class of crystalline materials comprised of organic ligands and lanthanide ions, have demonstrated a wide range of application prospects. Ln-MOFs possess unique characteristics of large stokes shift, wide emission range from ultraviolet-visible to near-infrared (NIR) as well as long luminescent lifetime [1-3]. So far, many UV-visible luminescent Ln-MOFs have been successfully constructed, while there are few reports on the use of NIR luminescent lanthanide complexes. Simultaneously, the near-infrared emitting materials which are of great interest for a variety of applications ranging from optical thermometry, telecommunications, sensing, anticounterfeiting to bioimaging [4-5]. However, they still suffer from some obvious shortcomings such as the presence of high-energy chemical bonds (such as $\mathrm{O}$ $\mathrm{H}, \mathrm{N}-\mathrm{H}$, and $\mathrm{C}-\mathrm{H}$ ) can largely act as an oscillator to significantly inhibit the near-infrared emission of lanthanide ions and the weak water-stability limits its application in the actual biological environment [6-7].

Hence, by anchoring functionalized ligands $(1,10-$ phenanthroline and 2,3,5,6-tetrafluoroterephthalic acid) and ytterbium ion onto its skeleton, we successfully synthesized a novel Yb-MOF-Y with high water stability and strong near-infrared emission mainly attributed to I) the selection of hydrophobic group $-\mathrm{F}$ and pyridine nitrogen can effectively improve water stability[8]. II) Choosing $\mathrm{Yb}$ ions as metal sites which can obtain the effect of near infrared emission [9-10]. III) The existence of multiple fluorine atoms and nitrogen atoms largely avoids high-energy bonds and guarantees strong nearinfrared emission [11].

\section{Experimental Section}

\subsection{Materials and Methods}

$\mathrm{Yb}\left(\mathrm{NO}_{3}\right)_{3} \cdot 5 \mathrm{H}_{2} \mathrm{O}, \quad 2,3,5,6$-tetrafluoroterephthalic acid ( $\mathrm{H}_{2} \mathrm{tfBDC}$ ), 1,10-phenanthroline (phen) and other reagents involved in this article were purchased and applied to the experiments directly. Single-crystal X-ray diffraction data for Yb-MOF-Y were recorded on a Bruker Apex CCD II area-detector diffractometer with graphite monochromated Mo-K $\alpha$ radiation $(\lambda=0.71073$ $\AA$ ) at 293(2) K. Absorption corrections were applied using the multi-scan technique. Their structures were solved by the direct methods of SHELXS-97 and refined by the full-matrix least-squares technique with the SHELXL-97 program.10 Non-hydrogen atoms were refined with anisotropic temperature parameters. The CCDC number of Yb-MOF-Y is 2016122.

\subsection{Synthesis of Yb-MOF-Y}

Under hydrothermal method, $\mathrm{Yb}\left(\mathrm{NO}_{3}\right)_{3} \cdot 5 \mathrm{H}_{2} \mathrm{O}(44.9 \mathrm{mg}$, $0.1 \mathrm{mmol}$ ), phen (35.7 $\mathrm{mg}, 0.15 \mathrm{mmol}$ ), and $\mathrm{H}_{2} \mathrm{tfBDC}$ $(29.7 \mathrm{mg}, 0.15 \mathrm{mmol})$ was dissolved in deionized water $(8 \mathrm{~mL})$. The fully mixed solution was then ultrasound for 12 minutes at room temperature and heated at $110^{\circ} \mathrm{C}$ for 2.5 days in $23 \mathrm{~mL}$ Teflon-lined autoclave. Then, the resulted colorless transparent block crystals (namely $\mathrm{Yb}$ MOF-Y) were obtained. Elemental analysis Calculated (\%) for Yb-MOF-Y [Yb(tfBDC $)_{1.5}($ phen $\left.)\left(\mathrm{H}_{2} \mathrm{O}\right)\right]_{\mathrm{n}}$

* Corresponding author: zmsu@,nenu.edu.cn 
$\mathrm{C}_{24} \mathrm{H}_{10} \mathrm{~F}_{6} \mathrm{~N}_{2} \mathrm{O}_{7} \mathrm{Yb}$ : C, 39.72; H, 1.38; N, 3.86. Found (\%): C, $40.01 ; \mathrm{H}, 1.39 ; \mathrm{N}, 3.91$.

\subsection{Water Stability Experiments}

Yb-MOF-Y (5mg) were dispersed in $5 \mathrm{~mL}$ of deionized water for 30 days; Yb-MOF-Y (5mg) were immersed in $5 \mathrm{~mL}$ of different $\mathrm{pH}$-value (3-11) aqueous solutions for 3 days, and Yb-MOF-Y (5mg) immersed in deionized water then heated them at $60{ }^{\circ} \mathrm{C}$ and frozen at $-20{ }^{\circ} \mathrm{C}$ for 3 days; subsequently, the PXRDs were detected.

\section{Results and discussion}

\subsection{Crystal structure of Yb-MOF-Y.}

Single-crystal $\mathrm{X}$-ray diffraction analyses demonstrate that $\mathrm{Yb}$-MOF-Y crystallizes belongs to the monoclinic space group $\mathrm{C} 2 / \mathrm{c}$ (Table 1 ). The asymmetric unit of $\mathrm{Yb}$ MOF-Y is assembled one crystallographically unique $\mathrm{Yb}^{3+}$ ions, 1.5 deprotonated $\mathrm{ffBDC}^{2-}$ ligands, one phen ligand and one terminal water molecules (Fig. 1a). The eight-coordinated $\mathrm{Yb}$ atom is composed of two $\mathrm{N}$ atoms are from one phen ligand and five carboxylate, five $\mathrm{O}$ atoms are from $1.5 \mathrm{H}_{2} \mathrm{tfBDC}$ ligands and one oxygen atoms from coordination water molecules (Fig.1b). The adjacent $\mathrm{Yb}^{3+}$ ions are connected orderly by oxygen atoms of the $\mathrm{H}_{2} \mathrm{tfBDC}$ ligands, forming a onedimensional chain, eventually further connected ligands to form a three-dimensional porous architecture (Fig. 1c, 1d).

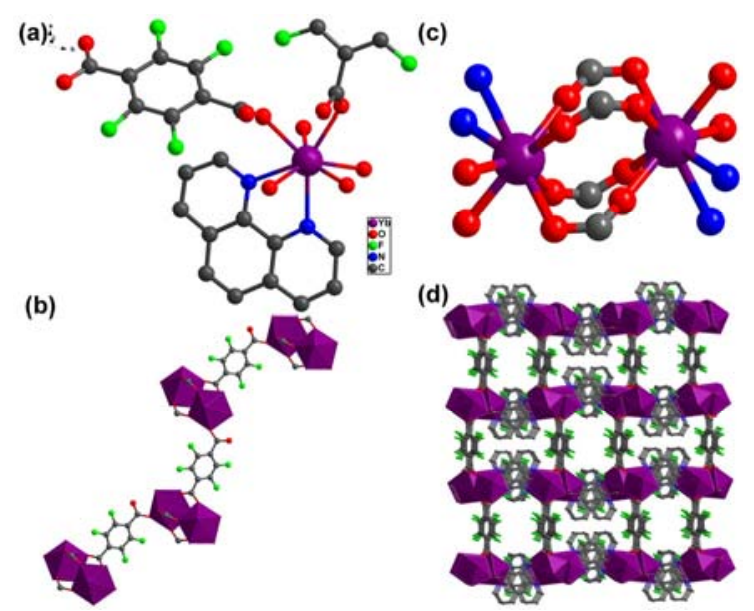

Fig. 1. (a) The asymmetric unit of Yb-MOF-Y. (b) Coordination of adjacent $\mathrm{Yb}^{3+}$ atoms. (c) 1D chain structure. (d) 3D structure. (Yb, purple; O, red; C, black; F, green; N, blue;)
Table 1. Crystal data and structure refinement details for $\mathrm{Yb}$ MOF-Y.

\begin{tabular}{|c|c|}
\hline & Yb-MOF-Y \\
\hline empirical formula & $\mathrm{C}_{24} \mathrm{H}_{10} \mathrm{~F}_{6} \mathrm{~N}_{2} \mathrm{O}_{7} \mathrm{Yb}$ \\
\hline formula weight & 725.38 \\
\hline crystal system & monoclinic \\
\hline space group & $\mathrm{C} 2 / \mathrm{c}$ \\
\hline $\mathrm{a}$ & $19.530(4) \AA$ \\
\hline $\mathrm{b}$ & $21.121(5) \AA$ \\
\hline $\mathrm{c}$ & $11.501(3) \AA$ \\
\hline$\alpha$ & $90^{\circ}$ \\
\hline$\beta$ & $101.307(8)^{\circ}$ \\
\hline$\gamma$ & $90^{\circ}$ \\
\hline volume & $4651.9(19) \AA^{3}$ \\
\hline $\mathrm{z}$ & 48 \\
\hline$\rho_{\text {calc }}$ & $2.071 \mathrm{~g} / \mathrm{cm}^{3}$ \\
\hline$\mu / \mathrm{mm}^{-1}$ & 4.120 \\
\hline $\mathrm{F}(000)$ & 2784.0 \\
\hline $\begin{array}{l}2 \Theta \text { range for data } \\
\text { collection }\end{array}$ & 5.284 to 50.152 \\
\hline $\begin{array}{l}\text { Independent } \\
\text { reflections }\end{array}$ & $\begin{array}{c}4124\left[\mathrm{R}_{\text {int }}=0.0614,\right. \\
\left.\mathrm{R}_{\text {sigma }}=0.0320\right]\end{array}$ \\
\hline goodness-of-fit on $\mathrm{F}^{2}$ & 1.029 \\
\hline $\mathrm{R}_{1}^{\mathrm{a}}[\mathrm{I}>=2 \sigma(\mathrm{I})]$ & $\mathrm{R}_{1}^{\mathrm{a}}=0.0253$ \\
\hline $\mathrm{wR}_{2}{ }^{\mathrm{b}}$ [all data] & $\mathrm{wR}_{2}{ }^{\mathrm{b}}=0.0518$ \\
\hline
\end{tabular}

\subsection{Characterization of Yb-MOF-Y}

Fig. 2a obviously shown that a good matching relationship between the powder X-ray diffraction peaks of $\mathrm{Yb}-\mathrm{MOF}-\mathrm{Y}$ obtained from the experiments and simulated data from the CIF file (CCDC number: 2016122), manifesting the highly crystalline structure and high phase purity of the synthesized Yb-MOF-Y. The TGA result of Yb-MOF-Y was shown in the Fig. 2b, the $\mathrm{Yb}-\mathrm{MOF}-\mathrm{Y}$ demonstrates excellent thermal stability (about $329{ }^{\circ} \mathrm{C}$ ), there is a $2.5 \%$ weight loss around $109{ }^{\circ} \mathrm{C}$ due to the release of one coordination water molecules. After exceeding $327^{\circ} \mathrm{C}$, the weight dropped significantly, indicating that its frame began to collapse. 

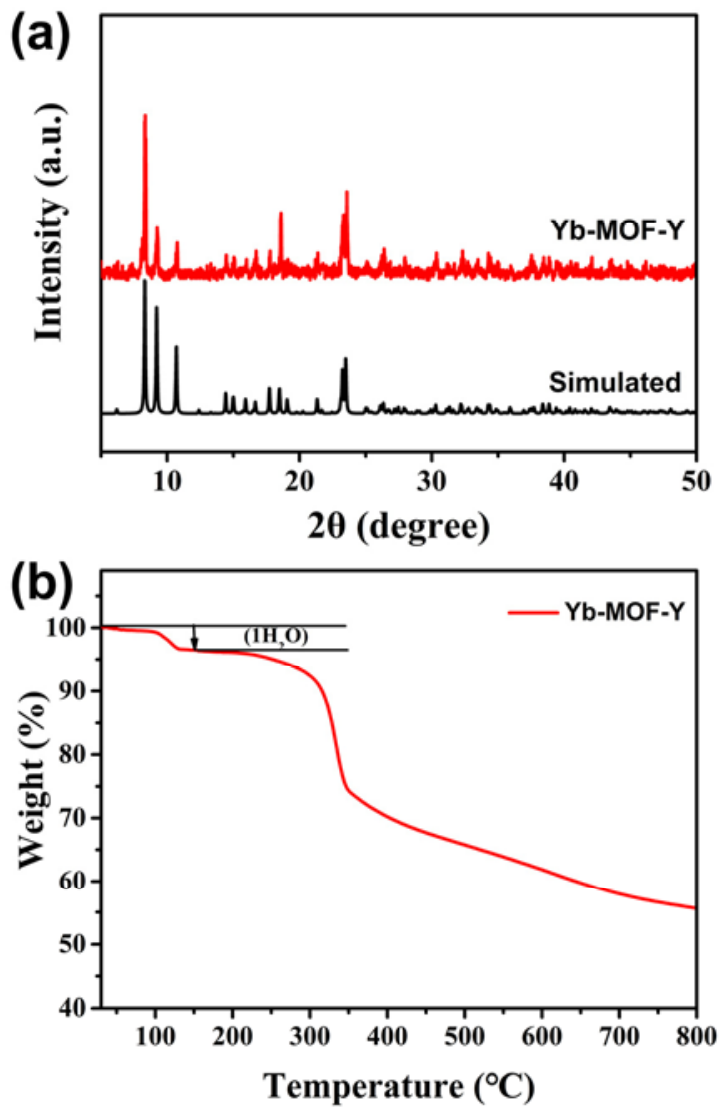

Fig. 2. (a) Simulated and experimental PXRD pattern of $Y b$ MOF-Y. (b) The TGA of Yb-MOF-Y.

\subsection{Luminescence properties of Yb-MOF-Y.}

As shown in the Fig.3, Upon exciting at $330 \mathrm{~nm}$, YbMOF-Y displays the characteristic emission of $\mathrm{Yb}^{3+}$ at $980 \mathrm{~nm}$ which can be attributed to the ${ }^{2} F_{5 / 2} \rightarrow{ }^{2} F_{7 / 2}$ transition [12].

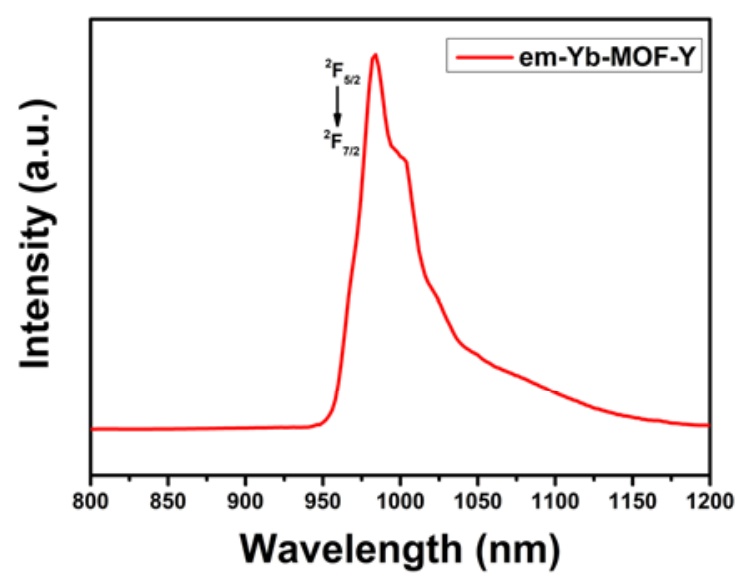

Fig. 3. Emission spectra of Yb-MOF-Y

The appearance of this strong near infrared emission peak is attributed to ligands with a much higher T1 triplet-state energy than the accepting level of metal ions, resulting in good energy transfer from the ligand to the $\mathrm{Yb}^{3+}$ metal site and the addition of multiple - $\mathrm{F}$ groups and pyridine nitrogen avoids the occurrence of high- energy bonds to suppress the appearance of near-infrared emissions.

\subsection{Water stability properties}

The water stability of MOF is critical because water is present in most biological processes. Therefore, the water stability of Yb-MOF-Y in different water environments was carried out by Powder X-ray diffraction. Fig. 4a, 4b show that the diffraction peaks of Yb-MOF-Y after immersion in water for 30 days, heating at $60{ }^{\circ} \mathrm{C}$, freezing at $-20{ }^{\circ} \mathrm{C}$ for 3 days and immersed in aqueous solutions with different $\mathrm{pH}$ values $(2-10)$ are in good agreement with the original Yb-MOF$\mathrm{Y}$, manifesting that $\mathrm{Yb}-\mathrm{MOF}-\mathrm{Y}$ has high water stability which may be due to the hydrophobic group and Ln-N coordination enhance the crystal's resistance to water molecules [13].
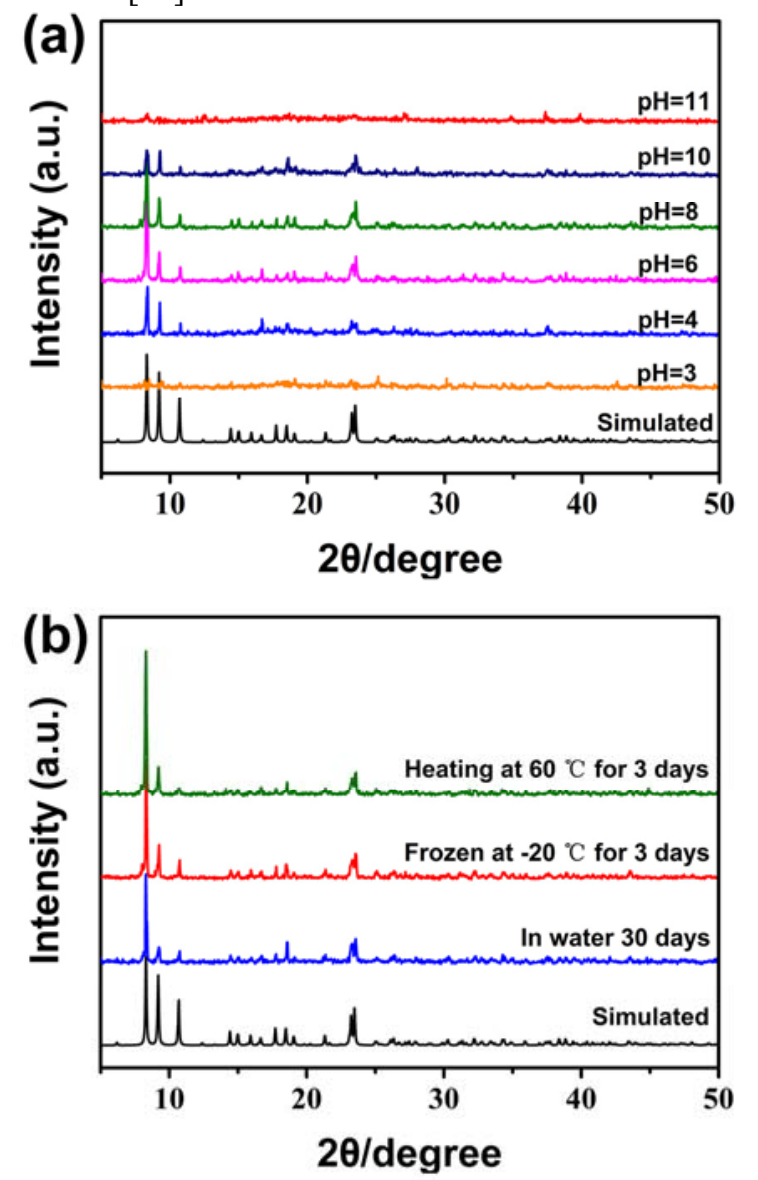

Fig. 4. (a) PXRD patterns of Yb-MOF-Y were immersed in water 30 days, frozen at $-20^{\circ} \mathrm{C}$, heated at $60{ }^{\circ} \mathrm{C}$ in water for 3

days. (b) PXRD patterns of Yb-MOF-Y were treated by aqueous solutions with various $\mathrm{pH}$ values (3-11).

\section{Conclusion}

In summary, guided by the strategy for the purposeful selection of functional ligands 2,3,5,6tetrafluoroterephthalic acid and 1,10-phenanthroline, a novel Ln-MOF-based near infrared luminescent materials (namely, Yb-MOF-Y) has been successfully prepared. The Yb-MOF-Y reveals high water stability, not only suitable for pure water, freezing and heating 
environment, but also can apply to acid-base aqueous solution $(\mathrm{pH}=4-10)$. The fluorescence detection results manifest that has strong emission at $980 \mathrm{~nm}$ which can be used as potential materials in the near infrared field.

\section{References}

1. H.H. Yu, M.Y. Fan, Q. Liu, Z.M. Su, X. Li, Q.Q. Pan, X.L. Hu, Two Highly Water-Stable ImidazoleBased Ln-MOFs for Sensing $\mathrm{Fe}^{3+}, \mathrm{Cr}_{2} \mathrm{O}_{7}{ }^{2-} / \mathrm{CrO}_{4}{ }^{2-}$ in a Water Environment. Inorg. Chem., 59 (2020) 2005-2010.

2. H.Q. Yin, X. B. Yin, Metal-Organic Frameworks with Multiple Luminescence Emissions: Designs and Applications. Acc. Chem. Res., 53 (2020) 485-495.

3. L.Yu, Q.T. Zheng, H. Wang, C.X. Liu, X.Q. Huang, Y.X. Xiao, Double Color Lanthanide Metal-Organic Framework Based Logic Device and Visual Ratiometric Fluorescence Water Microsensor for Solid Pharmaceuticals, Anal. Chem., 92 (2020) 1402-1408.

4. Q. Wen, Y. Zhang, C. Li, S. Ling, X. Yang, G. Chen, Y. Yang, Q. Wang, Self-Assembled Peptide Nanochain with NIR-II Fluorescence for Ultrasensitive Detection of Peritoneal Metastasis, Angew. Chem. Int. Ed., 58 (2019) 11001-11006.

5. H.F. Chen, X.P. Yang, D.M. Jiang, D. Schipperb, R.A. Jones, NIR luminescence for the detection of metal ions and nitro explosives based on a grape-like ninenuclear $\mathrm{Nd}(\mathrm{III})$ nanocluster, Inorg. Chem. Front., 6 (2019) 550-555.

6. H.H Yu, J.Q. Chi, Z. M. Su, X. Li, J. Sun, C. Zhou, X.L Hu, Q. Liu, A water-stable terbium metalorganic framework with functionalized ligands for the detection of $\mathrm{Fe}^{3+}, \mathrm{Cr}_{2} \mathrm{O}_{7}^{2-}$ ions in water and picric acid in seawater, CrystEngComm, 22 (2020) 3638-3643.

7. M.L. Ding, X.C. Cai, H.L. Jiang, Improving MOF stability: approaches and applications, Chem. Sci., 10 (2019) 10209.

8. Q. Liu, S.S. Li, H.H. Yu, F.M. Zeng, X. Li, Z.M. Su, Covalently crosslinked zirconium-based metalorganic framework aerogel monolith with ultralowdensity and highly efficient $\mathrm{Pb}(\mathrm{II})$ removal. Journal of Colloid and Interface Science, 561 (2020) 211219.

9. D. Zou, J. Zhang,Y. Cui, G. Qian, Near-Infraredemissive metal-organic frameworks, Dalton Trans., 48 (2019) 6669-6675.

10. T. N. Nguyen, G. Capano, A. Gladysiak, F. Ebrahim, S. Eliseeva, A. Chidambaram, B. Valizadeh, S. Petoud, B. Smit and K. Stylianou, Chem. Commun., 54 (2018) 6816-6819.

11. X.S. Lian, D. Zhao, Y.J Cui, Yu Yang, G.D. Qian, A Near Infrared Luminescent Metal-Organic Framework for Temperature Sensing in Physiological Range, Chem. Commun., 51 (2015) 17676-17679.
12. A. M. Kaczmarek, M. K. Kaczmarek and R. Van Deun, Nanoscale, 11 (2019) 833-837.

13. Q. Liu, H.H. Yu, F. M. Zeng, X. Li, J. Sun, X.L. Hu, Q.Q. Pan, C. Li, H. Lin, Z.M. Su, Polyaniline as interface layers promoting the in-situ growth of zeolite imidazole skeleton on regenerated cellulose aerogel for efficient removal of tetracycline. Journal of Colloid and Interface Science, 579 (2020) 119127. 